\title{
Effect of Addition of Dexamethasone or Clonidine to Ropivacaine on Postoperative Analgesia in Ultrasonography Guided Transversus Abdominis Plane Block for Inguinal Hernia Repair: A Prospective Double Blind Randomized Control Trial
}

\author{
Sweta Bharadiya ${ }^{1}$, Neelam Meena' ${ }^{2}$, Ram Nivas ${ }^{3}$, R. K. Solanki ${ }^{3}$ \\ ${ }^{1} 3^{\text {rd }}$ Year Resident, Department of Anaesthesiology and Critical Care, Dr. S. N. Medical College, Jodhpur, Rajasthan, India, ${ }^{2}$ Associate Professor, Dr S. N. \\ Medical College, Jodhpur, Rajasthan, India, ${ }^{3}$ SR Anaesthesia, Department of Anaesthesiology and Critical Care, Dr. S. N. Medical College, Jodhpur, \\ Rajasthan, India.
}

\section{Abstract}

Background: A hernia repair surgery commonly induces moderate to severe postoperative pain for 48 hours. Aim of the study was to compare $0.5 \%$ Ropivacaine with dexamethasone and $0.5 \%$ Ropivacaine with clonidine for ultrasonography guided transversus abdominis plane (TAP) block as post-operative analgesia in patients undergoing Inguinal hernia repair surgery. Subjects and Methods: A randomized prospective controlled clinical study was conducted in 64 patients undergoing Inguinal Herneoplasty. Participants were divided into two groups in which group RD ( $\mathrm{n}=32)$ received $0.5 \%$ Ropivavacaine with Dexamethasone 8mg and those in group RC ( $=32$ ) received $0.5 \%$ Ropivacaine with Clonidine $75 \mathrm{mcg}$ as USG guided TAP block at the end of surgery. The postoperative pain was evaluated by visual analog scale (VAS) for pain scoring at every 2 hours for 24 hours postoperatively. Subjective assessment of duration of analgesia was done. Results: Time to first rescue analgesia was significantly less in group RC $(424.53 \pm 34.13)$ compared to group RD $(616.09 \pm 31.36 \mathrm{~min})$ (P < 0.001). Total tramadol consumed in $24 \mathrm{~h}$ was significantly higher in group $\mathrm{RC}$ than group RD $(\mathrm{P}<0.001)$. Visual analog scale scores for both somatic and visceral pain were significantly higher in group RC than group RD at $6 \mathrm{~h}, 8 \mathrm{~h}$ and $12 \mathrm{~h}$ postoperatively. Conclusion: TAP block is a safe and effective way of relieving postoperative pain in inguinal herneoplasty patients. Addition of dexamethasone to Ropivacaine significantly enhances its effect in terms of block quality and analgesia duration as compared to clonidine addition.

Keywords: Clonidine, Dexamethasone, Ropivacaine.

Corresponding Author: Dr. Neelam Meena, Associate Professor, Dr S. N. Medical College, Jodhpur, Rajasthan, India. Email: drswetabhararia21@gmail.com

Received: February 2020

Accepted: February 2020

\section{Introduction}

Uncontrolled pain resulting from surgeries leads to endocrine, metabolic and inflammatory responses grouped together as surgical stress response which has adverse effects on various physiological functions. Inadequate analgesia may be associated with increased perioperative morbidity and mortality. Effective postoperative analgesia is an essential component of the care of surgical patients. ${ }^{[1]}$ Multiple approaches including pharmacology have been used in the pain management after inguinal hernia repair but an Optimal Pain Management is yet to be decided. ${ }^{[2]}$ Transversus abdominis plane block or Ilioinguinal/Iliohypogastric nerve blocks are few of many analgesic modalities used now a days to achieve optimum Postoperative analgesia following inguinal hernia surgery. TAP block is easy to perform and an effective peripheral abdominal field block that blocks the ilionguinal, Iliohypogastric and lower intercostal (T7-T11) nerves ${ }^{[3,4]}$ Addition of adjuvants to the local anaesthetic drug increases the potency, duration and quality of anaesthesia and postoperative analgesia in peripheral nerve block. ${ }^{[5-9]}$ Dexamethasove, very potent and highly selective glucocorticoid has been used to increase the duration of analgesia in peripheral nerve blocks. ${ }^{[10-12]}$ Clonidine is centrally acting $\alpha-2$ against addition of clonidine to local anaesthetics significantly prolongs the duration of motor block and Postoperative analgesia when used for Pheripheral nerve and plexus blocks. ${ }^{[13]}$

The aim of our study was to determine the effect of dexamethasone or clonidine on post-operative analgesia for inguinal hernia repair surgeries when added to $0.5 \%$ Ropivacaine in USG guided TAP block.

\section{Subjects and Methods}

This prospective, randomised, double blinded study was conducted after approval from Hospital's Ethical Committee over a period of 6 months. A written and informed consent 
was taken from the patient after explaining the procedure to the patient.

Patients with ASA I \& II, aged 18-60 years undergoing elective inguinal hernia repair were included in the study. Exclusion criteria included patient's refusal, Patient with known hypersensitivity to local anaesthetics, opioid addicted patients, bleeding diathesis, chronic systemic illness, infection at the site of block, patients with peripheral neuropathy and neurological deficits.

Patients were divided into two groups by randomization. Group RC $(\mathrm{n}=32)$ received $20 \mathrm{ml} 0.5 \%$ Repivacaine +75 mcg Cloridine with $1.5 \mathrm{ml}$ normal saline with total volume of $22 \mathrm{ml}$. Group RD $(\mathrm{n}=32)$ received $20 \mathrm{ml} \mathrm{0.5 \%}$ Ropivacaine + $8 \mathrm{mg}(2 \mathrm{ml})$ dexamethasone with total volume of $22 \mathrm{ml}$.

On arriving inside operating room, electrocardiogram (ECG), peripheral $\mathrm{O} 2$ saturation $(\mathrm{SpO} 2)$ probe and noninvasive arterial BP monitors were attached. A large bore cannula was inserted in a peripheral vein and pre-hydration was done with a crystalloid solution with a dose of $10 \mathrm{~mL} / \mathrm{kg}$ administered within 15 minutes. $\mathrm{ECG}$ and $\mathrm{SpO} 2$ were monitored continuously and noninvasive BP was recorded every 5 minutes during the intraoperative period in first half hour and at interval of every 15 minutes till the completion of surgery after that. The Patient was premedicated with $0.02 \mathrm{mg} / \mathrm{kg}$ Inj. midazolam. After preparing the skin with betadine followed by surgical spirit, spinal anaesthesia was administered using $3 \mathrm{ml}$ of $0.5 \%$ Inj. Bupivacaine(hyperbaric) at L3-4 or L4-5 interspace with 25 gauge Quincke's tip Spinal needle, under all aseptic precautions (B.Braun; Melsungen, Germany).

After completion of the surgical procedure, the patient was administered USG guided TAP block. First, skin was prepared with betadine and surgical spirit followed by draping with sterile cloth. The Ultrasound probe (M-turbo 11-mm broadband linear array, 6-14MHz; Sonosite, Bothell, Washington, USA) was sheathed. After identifying the lower costal margin and iliac crest, the ultrasound probe was placed in the mid-axillary line between them, in a transverse plane to the lateral abdominal wall in order to obtain a transverse view of the abdominal layers. The structures seen from surface to the depth were external oblique muscle, internal Oblique muscle, transversus abdominis muscle and peritoneal cavity (figure: 6B) 48. A $22 \mathrm{G}$ needle was inserted $1 \mathrm{~cm}$ medial to the probe and advanced using the in-plane technique with USG real-time assessment. The injection site was defined between aponeurosis of internal oblique and transversus abdominis muscles. After the tip of needle was correctly placed, $2 \mathrm{ml}$ drug was injected to expand the space followed by infusion of drug in $5 \mathrm{ml}$ increments with gentle intermittent aspiration. During the injection, the distribution of local anaesthetics was observed as a hypoechoic enlargement upon USG. Specific drug concentrations were prepared by individual anaesthesiologist who was not part of the study. Inj. Tramadol $1.5 \mathrm{mg} / \mathrm{kg}$ IV was given as recue analgesia when VAS scores more than 45 or on patient's demand.

The primary outcome of study was duration of analgesia which was defined as the time interval from completion of local anaesthetic administration till first demand of analgesic, quality of analgesia determined by VAS score at fixed intervals and total tramadol consumption. Secondary outcomes were postoperative adverse effects and complications (hemodynamic instability, respiratory depression, nausea, vomiting, transient femoral nerve palsy) and to compare effect of TAP block on vitals in term of heart rate, blood pressure, oxygen saturation and respiratory rate.

A power analysis based on time for analgesia in a previous study carried out on TAP block by Ammar A et al 14 revealed that 32 patients in each group were enough to detect difference in the duration of analgesia with a significant interval of $1 \mathrm{hr}$., with $\alpha$ error $=0.05, \beta$ error $=0.20$, power of study at $80 \%$ and confidence limit of $95 \%$. Statistical analysis was done using SPSS 23 software. The Kolmogorov-Smirnov test was used to verify the normal distribution of continuous variables. Continuous variables are expressed as mean \pm standard deviation or median with interquartile range as deemed appropriate. Normally distributed continuous variables were compared using unpaired Student's t-test. Z- test was performed for comparison of VAS scores and time for analgesia. Tramadol consumption was also compared using unpaired Student's ttest. Categorical variables were compared by the Chi-square test. All analyses were two tailed and $\mathrm{p}<0.05$ was considered statistically significant.

\section{Results}

Table 1: Comparison between two groups according to demographic data

\begin{tabular}{|l|c|c|c|}
\hline \hline \multicolumn{1}{|c|}{ Parameters } & Group RC & Group RD & P Value \\
\hline Age & $43.75 \pm 17.60$ & $43.46 \pm 16.46$ & $0.947(\mathrm{NS})$ \\
\hline ASA Grade & 18 & 15 & $0.453(\mathrm{NS})$ \\
\cline { 2 - 4 } & 14 & 17 & \\
\hline Weight & $73.84 \pm 8.23$ & $75.46 \pm 8.42$ & $0.438(\mathrm{NS})$ \\
\hline
\end{tabular}

Table 2: Comparison between two groups according to VAS score

\begin{tabular}{|c|c|c|c|c|c|c|}
\hline \multirow[b]{2}{*}{ VAS score } & \multicolumn{2}{|c|}{ Group $\mathrm{RC}$} & \multicolumn{2}{|c|}{ Group RD } & \multirow[b]{2}{*}{ z score } & \multirow[b]{2}{*}{ p value } \\
\hline & Median & $\begin{array}{l}\text { Interquartile } \\
\text { range(}(2,1,3)\end{array}$ & Median & $\begin{array}{l}\text { Interquartile } \\
\text { range }(2,1,3)\end{array}$ & & \\
\hline $2 \mathrm{hr}$ & 0 & $0,3.25$ & 0 & $0,4.25$ & -1.109 & 0.267 \\
\hline 4hir & 12 & 9,16 & 12 & 10,15 & 0.344 & 0.73 \\
\hline $6 \mathrm{hr}$ & 31 & 29,33 & 30 & 27,32 & 1.394 & 0.163 \\
\hline 8hr & 47 & 44,48 & 32 & 29,35 & 13.43 & $<0.0001 *$ \\
\hline 10hr & 53 & 50,55 & 41 & 39,4 & 9.963 & $<0.0001 *$ \\
\hline 12hr & 61 & 58,63 & 52 & 50,56 & 6.611 & $<0.0001 *$ \\
\hline 18hr & 59 & 57,61 & 58 & 56,60 & 0.378 & 0.704 \\
\hline 24hr & 60 & 60,67 & 60 & 60,65 & 0.715 & 0.474 \\
\hline
\end{tabular}




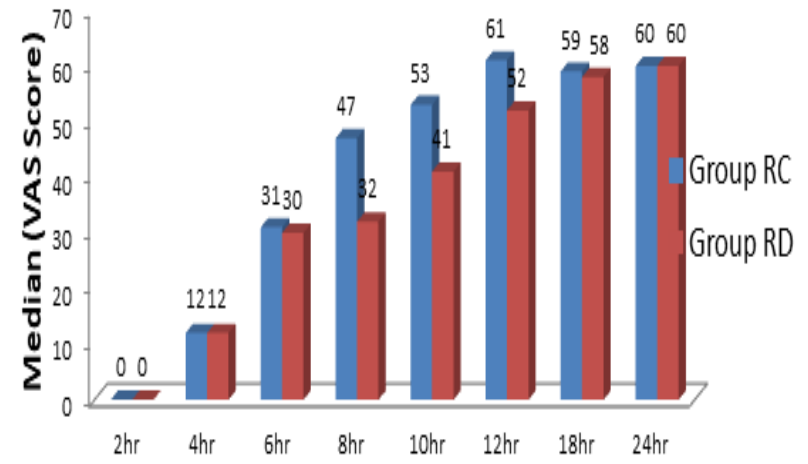

Figure 1: Change in Visual Analogue Scale score

Both groups were matched for the demographic data [Table 1]. There was significant difference in VAS scores of group $\mathrm{RC}$ and $\mathrm{RD}$ from $8^{\text {th }}$ to $12^{\text {th }}$ hour of postoperative period. Patients in group RD had significantly lower VAS scores as compared to group RC $(\mathrm{p}<0.05)$ [Figure $1 \&$ Table 2]. Duration of analgesia was significantly more in group RD [547.50(530,530) $\mathrm{min}]$ when compared with group RC [387.50 $(370,400) \mathrm{min}](\mathrm{p}<0.05)$ [Table 3]. The demand for rescue analgesic i.e. Inj. tramadol was significantly low in group RD $(184.37 \pm 57.41 \mathrm{mg})$ as compared to group $\operatorname{RC}((231.25 \pm 64.44 \mathrm{mg}) \quad(\mathrm{p}<0.05) \quad$ [Table 3]. There was significant difference in Ramsay sedation score. Score of 2 in group $\mathrm{RD}$ in more number of patients as compared to group RC ( $\mathrm{p}<0.05)$ [Table 4]. The incidence of nausea and vomiting was higher in group $\mathrm{RC}$ when compared to group RD. Lower incidence of vomiting in group RD can be attributed to antiemetic property of dexamethasone and decreased doses of tramadol $(184.37 \pm 57.41 \mathrm{mg})$ [Table 5]. Complications like hypotension, bradycardia, transient femoral palsy and urinary retention did not happen.

Table 3: Comparison between the results of two groups

\begin{tabular}{|l|l|l|l|}
\hline & Group RC(n=32) & $\begin{array}{l}\text { Group } \\
\mathbf{R D}(\mathbf{n}=32)\end{array}$ & P value \\
\hline $\begin{array}{l}\text { Duration of } \\
\text { analgesia }\end{array}$ & $387.50(370,400)$ & $547.50(530,580)$ & $<0.05$ \\
\hline $\begin{array}{l}\text { Total opioid } \\
\text { consumption }\end{array}$ & $231.25 \pm 64.44$ & $184.37 \pm 57.41$ & $<0.05$ \\
\hline
\end{tabular}

Data expressed as Median (interquartile range)

Data expressed as Mean \pm standard deviation

Table 4: Ramsay Sedation Score

\begin{tabular}{|l|l|l|l|l|}
\hline \multirow{2}{*}{$\begin{array}{l}\text { Ramsay } \\
\text { sedation score }\end{array}$} & Group RC & \multicolumn{2}{l|}{ Group RD } \\
\cline { 2 - 5 } & N & \% & N & \% \\
\hline 2 & 14 & 43.75 & 27 & 84.38 \\
\hline 3 & 18 & 56.25 & 5 & 15.63 \\
\hline
\end{tabular}

\section{Discussion}

In our study, addition of dexamethasone to ropivacaine in TAP block significantly improved the duration of analgesia. The time for analgesia (TFA) in group RD was 547.50 $(530,580) \mathrm{min}$ which was significantly longer than 387.50 $(370,400)$ min of group RC $(\mathrm{p}<0.05)$. This observation was also consistent with findings of previously done studies. ${ }^{[14,5]}$ Addition of dexamethasone to local anaesthetics as an adjuvant increases the duration of peripheral block. Dexamethasone exerts its analgesic action by inhibiting transmission and neural discharge in nociceptive C-fibers. ${ }^{[16]}$ Hence the duration of anaesthesia is prolonged due to dexamethasone's additive action. Addition of dexamethasone to ropivacaine in TAP block resulted in significant reduction of tramadol consumption. Mean tramadol consumption in group RC (231.25 $\pm 64.44 \mathrm{mg})$ was significantly higher when compared to group RD $(184.37 \pm 57.41 \mathrm{mg})(\mathrm{p}<0.05)$. This finding was consistent with previously done studies. ${ }^{[14,17]}$ Clonidine along with Ropivacaine for prolonging analgesic duration also had significant sedative effect but arousable sleep. The mean sedation score of 3 was obtained in $56.25 \%$ patients in RC group compared to $15.63 \%$ in RD group. Results were consistent with previously done studies. ${ }^{[18]}$

Table 5: Comparison between Postoperative side effects between two group.

\begin{tabular}{|c|c|c|c|c|c|}
\hline \multirow{2}{*}{$\begin{array}{c}\text { Side } \\
\text { effects }\end{array}$} & \multicolumn{2}{|c|}{ Group RC } & \multicolumn{2}{|c|}{ Group RD } & \multirow{2}{*}{ p value } \\
\cline { 2 - 5 } & $\mathrm{N}$ & $\%$ & $\mathrm{~N}$ & $\%$ & \\
\hline Nausea & 7 & 21.88 & 4 & 12.50 & 0.509 \\
\hline Vomiting & 3 & 9.38 & 1 & 3.13 & 0.612 \\
\hline Headache & 3 & 9.38 & 3 & 9.38 & 1.328 \\
\hline $\begin{array}{c}\text { Dry } \\
\text { mouth }\end{array}$ & 3 & 9.38 & 1 & 3.13 & 0.612 \\
\hline
\end{tabular}

There was decreased incidence of nausea in group $\mathrm{RD}$ as compared to group $\mathrm{RC}(\mathrm{p}=0.509)$. The incidence of vomiting was also decreased $(p=0.612)$ but incidence of other side effects was statistically comparable. Conclusions were similar to previously done studies. ${ }^{[14,19]}$ Dexamethasone and related glucocorticoids are believed to act via various mechanisms ranging from their anti-inflammatory effect to regulation of the hypothalamic-pituitary-adrenal axis. Dexamethasone also acts directly at the solitary tract nucleus, interact with the neurotransmitter serotonin, and receptor proteins tachykinin NK1 and NK2, alpha-adrenaline, etc., maintain the normal physiological functions of organs and systems and also reduce pain and the concomitant use of opioids, which in turn reduces opioid-related nausea and vomiting.

In our study, complications like local anaesthetic toxicity, haematoma at local site, excessive tissue trauma and femoral nerve palsy were not observed. This result could probably be due to USG guidance that enabled better visualization of the abdominal structure before injection.

Our limitation of the current study are study was conducted upon patients undergoing Inguinal hernia surgeries only and the results cannot be extrapolated to other surgeries conducted under spinal anaesthesia, study was conducted in a single centre service hospital. Results cannot be generalized to the population of other countries, Numeric rating pain scale is not an objective method and there could be some variability in the patient's ability to use this scale and another theoretical limitation of our study was enrolment of only male participants. This was not by study design but more a result of fact tha inguinal hernia pathology is much more 
common in men than women.

\section{Conclusion}

We conclude from our study that the addition of dexamethasone to ropivacaine compared to Clonidine in USG guided TAP block significantly reduced the intensity of postoperative pain and prolonged the duration of postoperative analgesia, thereby reducing analgesic consumption and associated adverse effects. Also, dexamethasone can be considered as a safe adjuvant to TAP block with no potential side effects.

\section{References}

1. Kehlet H. Surgical stress. The role of pain and analgesia. Br J Anaesth. 1989; 63:189-95

2. Joshi GP. Multimodal analgesia techniques and postoperative rehabilitation. Anesthesiol Clin North Am. 2005; 23:185-202.

3. Demirci A, Efe EM, Türker G, Gurbet A, Kaya FN, Anil A, et al. Iliohypogastric/ilioinguinal nerve block in inguinal hernia repair for postoperative pain management: comparison of the anatomical landmark and ultrasound guided techniques. Brazilian $\mathbf{J}$ Anesthesiol. 2014; 64(5):350-6.

4. Wang Y, Wu T, Terry MJ, Eldrige JS, Tong Q, Erwin PJ, et al. Improved perioperative analgesia with ultrasound-guided ilioinguinal/iliohypogastric nerve or transversus abdominis plane block for open inguinal surgery: a systematic review and meta-analysis of randomized controlled trials. J Phys Ther Sci. 2016 Mar; 28(3):105560 .

5. Karakaya D, Buyukgoz F, Baris S. Addition of fentanyl to bupivacaine prolongs anesthesia and analgesia in axillary brachial plexus block. Reg Anesth Pain Med 2001; 26:434 8.

6. Fanelli G, Casati A, Magistris L. Fentanyl does not improve the nerve block characteristics of axillary brachial plexus anesthesia performed with ropivacaine. Acta Anaesthesiol Scand 2001; 45:590 4.

7. Kapral S, Goolann G, Walt B. Tramadol added to mepivacaine prolongs the duration of an axillary brachial plexus blockade. Anesth Analg 1999; 88: 853-85
8. Iohom G, Machmachi A, Diarra DP. The effects of clonidine added to mepivacaine for paronychia surgery under axillary brachial plexus blockade. Anesth Analg 2005; 100: 1179-1183

9. Noyan A. On effects of ketamine to axillary block in hand surgery. J ReconstrMicrosurg 2002; 18:197

10. Cummings KC, Napierkowski DE, Parra-Sanchez I, Kurz A, Dalton JE, Brems JJ, et al. Effect of dexamethasone on the duration of interscalene nerve blocks with ropivacaine or bupivacaine. Br J Anaesth. 2011, 107(3):446-53.

11. Khafagy HF, Refaat AI, El-Sabae HH, Youssif MA. Efficacy of epidural dexamethasone versus fentanyl on postoperative analgesia. J Anesth. 2010; 24:531-6.

12. Hong JY, Han SW, Kim WO, Kim EJ, Kil HK. Effect of dexamethasone in combination with caudal analgesia on postoperative pain control in day case paediatricorchiopexy. Br J Anaesth. 2010; 105:506-10.

13. Popping DM, Elia N, Marret E, Wenk M, Tramer MR. Clonidine as an adjuvant to local anaesthetics for peripheral nerve and plexus blocks; a meta analysis of randomised trials. Anesthesiology 2009; 111:406-15.

14. Ammar A, Mahmoud K. Effect of adding dexamethasone to bupivacaine on transversus abdominis plane block for abdominal hysterectomy: A prospective randomized controlled trial. Saudi J Anaesth. 2012; 6(3):229-33.

15. Falia MD, Kulkarni $P$ et al. Comparison of dexamethasone and clonidine as an adjunct to bupivacaine in TAP block patients undergoing lower segment caesarean section. Int J Res Med Sci 2016; 4: 4481-6

16. Johansson A, Hao J, Sjölund B. Local corticosteroid application blocks transmission in normal nociceptive C-fibres. Acta Anaesthesiol Scand 1990; 34:335-8.

17. Fouad HA, Mohammed A, Ahmed S, Mohammed Y, Osman M, Mohammed G, et al. Efficacy of preemptive dexamethasone added to bupivacaine in ultrasound guided Transversus abdominus plain block for postoperative analgesia after inguinal herniorrhaphy. Am J Res Commun. 2016; 4(5): 27-42

18. Casati A, Magistris L, Beccaria P, Cappelleri G, AldegheriG, Fanelli G.Improving postoperative analgesia after axillary brachial plexus anesthesia with $0.75 \%$ ropivacaine. A double blind evaluation of adding clonidine. Minerva Anesthesiol2001; 67:407-12.

19. Chu CC, Hsing CH, Shieh JP, Chien CC, Ho CM, Wang JJ. The cellular mechanisms of the antiemetic action of dexamethasone and related glucocorticoids against vomiting. Eur J Pharmacol. 2014;72:48-54.

Copyright: (C) the author(s), 2020. It is an open-access article distributed under the terms of the Creative Commons Attribution License (CC BY 4.0), which permits authors to retain ownership of the copyright for their content, and allow anyone to download, reuse, reprint, modify, distribute and/or copy the content as long as the original authors and source are cited.

How to cite this article: Bharadiya S, Meena N, Nivas R, Solanki RK. Effect of Addition of Dexamethasone or Clonidine to Ropivacaine on Postoperative Analgesia in Ultrasonography Guided Transversus Abdominis Plane Block for Inguinal Hernia Repair: A Prospective Double Blind Randomized Control Trial. Acad. Anesthesiol. Int. 2020;5(1):74-77.

DOI: dx.doi.org/10.21276/aan.2020.5.1.15

Source of Support: Nil, Conflict of Interest: None declared. 